\title{
Analytical Modification of Seismic Effect on the Building
}

\author{
Vladimir Leonidovich Kurbatov ${ }^{1} \&$ Natalia Dementyevna Komarova ${ }^{1}$ \\ ${ }^{1}$ North Caucasus branch of the federal government's budget educational institution of higher professional \\ education "Belgorod State Technological University named after V.G. Shukhov, Russia \\ Correspondence: Natalia Dementyevna Komarova, North Caucasus branch of the federal government's budget \\ educational institution of higher professional education "Belgorod State Technological University named after \\ V.G. Shukhov, Mineralnye Vody, Stavropol Territory, 357202, Russia. E-mail: natalia.komarova.2014@mail.ru
}

\author{
Received: October 17, $2014 \quad$ Accepted: October 27, $2014 \quad$ Online Published: December 10, 2014 \\ doi:10.5539/mas.v9n3p10 \\ URL: http://dx.doi.org/10.5539/mas.v9n3p10
}

\begin{abstract}
The article is devoted to the description of the analytical method of reducing the horizontal surface seismic effect transmission to the building or structure during an earthquake. The impact reducing effect can be achieved by the constructive inclusion of compensating underlayment of a highly deformable material with low modulus in shear which is located between the foundation and the bottom slab of the building. The dependence of the of underlayment compensating properties on its physical characteristics is shown.
\end{abstract}

Keywords: seismic effect, underlayment, peak value, structures, the effect of influence, deforming material

\section{Introduction}

Extensive program of theoretical and experimental studies of seismic isolation was initiated in the laboratory CNIISK Earthquake Engineering in early 1970 (Abowski, N. P. et al., 2010, Liu, T. et al, 2014, Mamaeva G. V. et al., 2001). In recent decades experimental and theoretical studies of various kinds of seismic isolation were also carried out by V.V. Nazin, Yu. G. Jaremenko, M.A. Dashevskiy and others. In recent years, studies on seismic isolation are intensively developed in Japan, USA, New Zealand, Italy and other countries.

(1) Seismoisolation is the modern technology of seismic protection which is providing decrease in seismic impact on constructions at an earthquake and proved the efficiency and economic competitiveness in comparison with usual ways of ensuring seismic stability of various constructions, such as bridges, civil buildings, historical monuments and responsible constructions. Experts of Russia and foreign countries offered various devices of systems of seismoisolation and quenchers of energy of fluctuations of constructions, and also systems with use of the alloys which are memorable a volume state, and other "intellectual" systems.

Development of tool seismology, deepening of understanding of the purposes and criteria of aseismic design, methods of dynamics of constructions, computerization of researches, emergence of new materials - all this became a basis for creation of the modern, evidence-based theory of seismoisolation and for broad application of seismoisolation in practice.

(2) At design of the buildings and constructions intended for construction in seismic countries, their seismic stability traditionally is provided by increase of the bearing ability of designs at the expense of increase in the sizes of the bearing elements and durability of materials, and also a number of constructive actions. However the theory of calculation of SSI is developed insufficiently so far. There is no consensus on seismoisolation damping control. Many of the used technical solutions are considered debatable from the point of view of their efficiency and safety. There are no uniform recommendations about selection of parameters of seismoisolation. Correct modeling of settlement seismic influence is defining for the solution of the questions posed at design.

(3) Design of buildings and constructions in seismically dangerous areas begins with observance of the all-believing principles of aseismic construction according to which all used construction materials, designs and constructive schemes have to provide the smallest value of seismic loadings. It is necessary to observe the requirement of uniform strength of elements of the bearing designs, loose knots and elements which premature exit can lead to destruction of a construction, before exhaustion of the ability bearing it shouldn't be allowed. In buildings and constructions from prefabricated elements it is recommended to have joints out of a zone of the maximum efforts, it is necessary to provide uniformity and solidity of designs due to use of the strengthened prefabricated elements. It is necessary to provide the conditions facilitating development of plastic deformations, 
providing thus the general stability of a construction in designs and their connections.

(4) The choice of space-planning schemes, their form and dimensions has essential impact on seismic stability of buildings. In modern aseismic construction the exclusively actual

value gets ensuring reliability of buildings and constructions on condition of a rational consumption of additional materials, means and labor costs on their aseismic strengthenings. The traditional way of ensuring seismic stability of constructions provides increase of the bearing ability of designs at the expense of increase in their sizes and durability of materials, and in buildings with the bearing brick walls application of aseismic belts, ferroconcrete inclusions, additional reinforcing of piers, crossings of longitudinal and cross walls, all this demands essential increase in amount of construction materials and means. The increase in amount of material conducts to increase in rigidity and weight of a construction that in turn causes increase in inertial loadings.

The active method allows to reduce seismic loads of the building on means of regulation of their dynamic characteristics, during oscillatory process at an earthquake. Regulation of dynamic parameters is carried out thus to avoid resonant increase in amplitudes of fluctuations of a construction, or at least to lower resonant effects.

(5) Change of dynamic rigidity or frequencies (periods) of own fluctuations

at an earthquake it can be reached with use of special constructive devices, such as the sliding belts, the switching-off communications, the quenchers of fluctuations, the kinematic bases, the pile bases possessing the raised dissipative characteristics frame связевые system with compound diaphragms of rigidity, rezino-steel cylindrical support and so forth.

The main condition of effective work of such systems is remoteness of frequencies of their own fluctuations from the prevailing frequencies of the seismic movement of soil of the basis of a construction.

(a) The seismoisolating systems with the switching-off communications (SOC) to avoid possibility of dangerous resonant fluctuations of the building with the ground flexible floor at earthquakes with the big prepotent periods, in TsNIISK of Kucherenko the design of buildings with the switching-off communications was developed [6,18]. The system of VS is called adaptive and intended for decrease in the inertial loadings in the building arising at seismic influence. Seismoisolation (VS) includes a rigid svyazevy element (a buttress, the svyazevy panel or other rigid design) and especially switching off elements (the collapsing details). A lack of this technical solution is that after destruction of the joining communications, during an earthquake their immediate restoration is necessary that isn't always almost feasible.

(b) Dynamic quenchers of fluctuations (QF)

Except the systems mentioned above for reduction of the inertial forces arising in constructions at earthquakes use systems with the raised characteristics of attenuation. Depending on constructive performance of elastic communications dynamic quenchers share on three groups:

- Spring

- Pendular

- Combined

The lack of this technical solution consists in complexity of systems and big material inputs on their contents.

\section{The Main Part}

\subsection{Method of Reduction of Seismic Influence of a Gorozontalny Surface}

The article is devoted to analytical description of the proposed (Fuller, C. R. et al., 1996; Harrison , J., 2006) method modifications. It's a method of reducing the horizontal surface of the seismic effect transmitting to the building or structure during an earthquake. The reducing effect is achieved through constructive inclusion of compensating underlayment (i.e. seismic isolation) of a highly deformable material with low modulus in shear (for example: rubber, neoprene), located between the foundation and the bottom slab of the building.

Figure 1 shows the block diagram of the system "building-underlayment-base." Horizontal surface seismic effect on the structure base $-\mathrm{Wb}=\mathrm{Wb}(\mathrm{t})$ - is defined by the harmonic relation:

$$
\mathrm{Wb}=\text { [delta] } \sin \text { [omega] } \mathrm{t} \text {, }
$$

where [delta] is its peak value, [omega] is the horizontal oscillations circular frequency. 


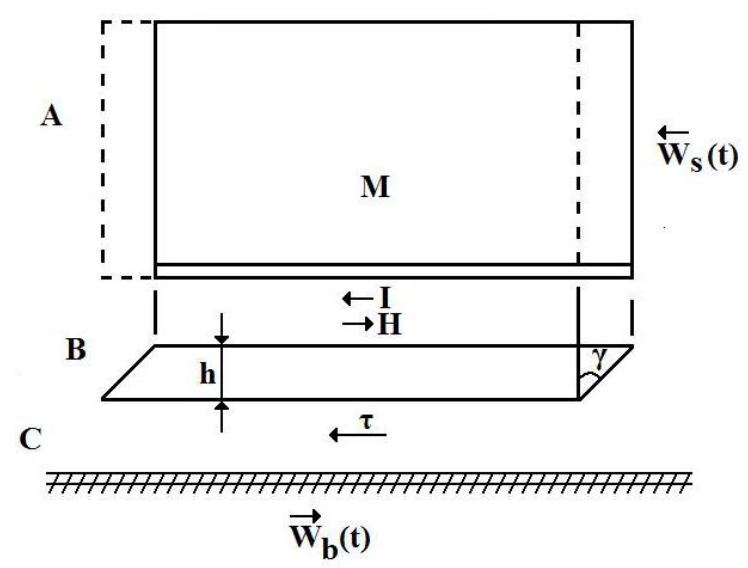

Figure 1. The basic design scheme

Note. A- structure, B - underlayment, C - base, M - structure mass, Wb - moving of base, Ws - moving of structure.

Let's assume that the underlayment material has both elastic and viscous properties, with $\mathrm{G}$ - modulus in shear and $[\mathrm{mu}]$ - the dynamic viscosity; [G], $\mathrm{g} * \mathrm{~cm} 2,[[\mathrm{mu}]], \mathrm{g} * \mathrm{~s} / \mathrm{sm} 2$. The thickness of layer (h) - is small in comparison with the linear dimensions of other structure elements. The structure will be regarded as a hard disk with $\mathrm{M}$ - mass and F - the area of bearing on its bottom slab. The hard disk makes horizontal vibrations caused by seismic effect according to the law:

$$
\mathrm{Ws}=\mathrm{Ws}(\mathrm{t})=\mathrm{a} \sin \text { [omega] } \mathrm{t} 4-\mathrm{b} \cos \text { [omega] } \mathrm{t},
$$

where $a$ and $b$ are linear values which should be defined.

Obviously, the Ws representation in the form (2), which is different from the relation (1), is in both cases determined by base and structure fluctuations phase shifting.

Horizontal movement within the underlayment is characterized by its shear deformation [gamma] = [gamma] (t). In this case, the wave phenomena through its thickness are not taken into account, in contrast to the wave processes in the massive soil layers of structure foundation (Analytical Fracture Mechanics, 1995; Kuznetsov, S. V., 2014; Krupko T. Y., June 2010).

Thus, in accordance with (1) and (2):

$$
\begin{gathered}
\gamma=\frac{W_{0}-W_{c}}{h}=\frac{\Delta \sin \omega t-(\alpha \sin \omega t+\beta \cos \omega t)}{h} \\
\gamma=\frac{d \gamma}{d t}=\frac{\omega}{h}[\Delta \cos \omega t-(\alpha \cos \omega t-\beta \cos \omega t)]
\end{gathered}
$$

Shear stress- $[\mathrm{tau}]=[\mathrm{tau}](\mathrm{t})-$ within the layer modeled by visco-elastic body is determined by the obvious relation:

$$
\tau=\gamma G+\gamma \mu
$$

and the total value of the shear force $-\mathrm{H}-$, transmitting on construction by the underlayment, has the form:

$$
\mathrm{H}=\tau * \mathrm{~F}
$$

Denoting $I=I(t)$ - the value of the horizontal inertial force acting on the structure, through:

$$
\mathrm{I}=\mathrm{m} \ddot{W}_{2}=-\mathrm{M}[\text { omega }]^{2}(\alpha \sin \omega \mathrm{t}+\beta \cos \omega \mathrm{t}),
$$

based on the dynamic equilibrium condition:

$$
\mathrm{H}+\mathrm{I}=0(8)
$$

due to $(3) \div(8)$ relation, we obtain: 


$$
G[\Delta \sin \omega t-(\alpha \sin \omega t+\beta \cos \omega t)]+\mu \omega[\Delta \cos \omega t-(\alpha \cos \omega t-\beta \sin \omega t)]=\frac{M \omega^{2} h}{F(\alpha \sin \omega t+\beta \cos \omega t)}
$$

Next, we introduce the notation: $\mathrm{G} /[$ omega $]=[\mathrm{phi}], \mathrm{M}$ [omega] h / F = m; [[phi]] -> [m] ... g* s/sm2. Taking them into account, grouping members of (9) in sin [omega] $t$ and cos [omega] $t$, and equating the corresponding independent expressions, we obtain a system of two linear algebraic equations for determining the unknown quantities a and $b$ :

$$
\begin{gathered}
(m+\varphi)-\mu \beta=\Delta \varphi(10) \\
\mu \alpha+(m+\varphi) \beta=\Delta \mu
\end{gathered}
$$

Solving system (10), we find:

$$
\begin{gathered}
\alpha=\Delta \frac{(\varphi+m) \varphi+\mu^{2}}{(\varphi+m)^{2}+\mu^{2}} \\
\beta=\Delta \frac{\mu m}{(\varphi+m)^{2}+\mu^{2}}
\end{gathered}
$$

$\alpha$ In accordance with (2), we write the final expression for the time law of structure horizontal displacements:

$$
W_{c}(t)=\frac{\left[(\varphi+m) \varphi+\mu^{2}\right] \sin \omega t+m \mu \cos \omega t}{(\varphi+m)^{2}+\mu^{2}} \Delta
$$

Peak value of Ws - value $\delta=\left(\alpha^{2}+\beta^{2}\right)^{0.5}$

$$
\delta=\left[\frac{\left(\varphi^{2}+\mu^{2}\right)}{(\varphi+m)^{2}+\mu^{2}}\right] \Delta
$$

\subsection{Assessment of Influence of the Compensating Properties of the Spreading Layer}

To assess the impact of compensating properties of underlayment in relation to the values of its physical characteristics: $\mathrm{G}$ and [mu], it is convenient to introduce the quantity of [epsilon] = [delta] / [delta] (Mokhtari, M. A. et al., 2003, Recommendations for the design of buildings with seismic isolation sliding sash and dynamic damper, 1984, Roaf, S. et al., 2010).

Figure 2 is a perspective view of the surface in the coordinate system of [phi] [mu] [epsilon] (13). If the layer material has a perfect elasticity $([\mathrm{mu}]=0)$, relationship $(13)$ defines:

$$
\varepsilon=\frac{1}{1+(m / \varphi)}
$$

If the material has a perfect viscosity $(\varphi=0)$ :

$$
\varepsilon=\frac{1}{\left[1+(m / \varphi)^{2}\right]^{0.5}}
$$

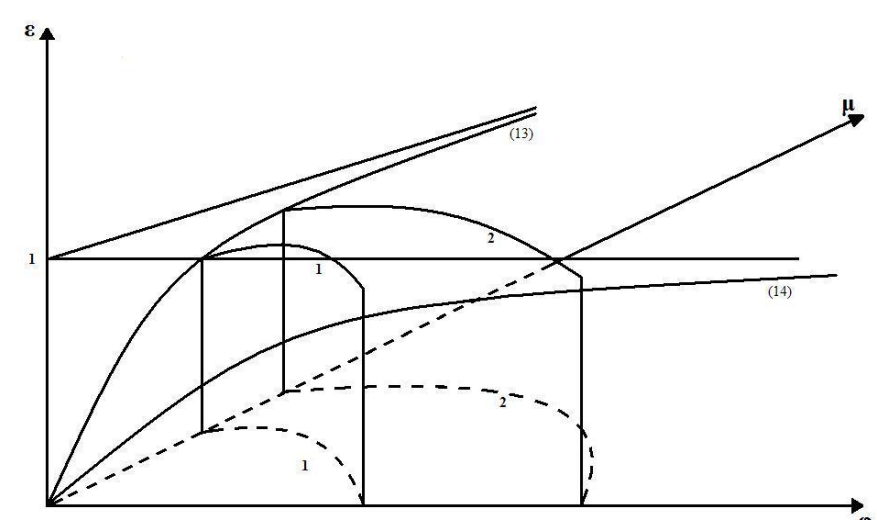

Figure 2. General view of the surface (13) in [phi][mu][epsilon]system

$1-[$ epsilon $]=\sqrt{0.5}, 2$ - [epsilon $]=0,8$. 
However, the latter case is purely hypothetical, as real materials have finite $G$ values, and when $G \rightarrow 0$, the Young's modulus $\mathrm{E} \rightarrow 0$ and operational thickness of the underlayment $-\mathrm{h}$ - at a finite value of the structure vertical pressure tends to zero (Geniyev, G. A. and Mamaeva, G. V., 2000; Harrison, H. R. and Nettleton, T., 1997; Harrison, J., 2006).

Relationship analysis (13) shows that loss in value of [epsilon], corresponding to the amplitude loss [delta] at ceteris paribus, occurs when:

- values of $\mathrm{m}$ increases, i.e. with increasing $\mathrm{M}$ and $\mathrm{h}$ values,

- the quantities of $\mathrm{G}$ and $[\mathrm{mu}]$ characteristics reduce,

- circular oscillation frequency- [omega]- increases.

Obviously, the quantity of [epsilon] determines the degree of reduction of the structure acceleration (Ẅs) peak value compared with the acceleration amplitude of the seismic effect $(\ddot{\mathrm{Wb}})$.

Figure 2 also shows the lines of equal level- [epsilon] = const- on the surface (13), corresponding to values: [epsilon $]=\sqrt{0.5}-$ line $1 ;$ Epsilon $]=0,8-$ line 2 .

Figure 3 shows these lines projections on the [phi] [mu], which are the circles of Ri (radii), with their centers being located on the axis of $[\mathrm{phi}]([\mathrm{mu}]=0)$ at the points of $\mathrm{Ci}$ :

$$
\left(\varphi-\mathrm{C}_{\mathrm{i}}\right)^{2}+\mu^{2}=\mathrm{R}_{\mathrm{i}}^{2}
$$

$$
\text { In addition, } R_{i}=\frac{\varepsilon}{\left(1-\varepsilon^{2}\right)} m
$$

$$
C_{i}=\frac{\varepsilon^{2}}{\left(1-\varepsilon^{2}\right)} m=R_{i} \varepsilon
$$

at $\varepsilon=\sqrt{0.5}-R_{1}=\sqrt{2} * m, C_{1}=m, \varphi_{\max }=(\sqrt{2}+1) m$;

at $\varepsilon=0.8-R_{2}=\frac{20 m}{9}, C_{2}=\frac{16 m}{9}, \varphi_{\max }=4 m$.

Figure 3 also shows the peak surface slope line projection on the [phi] [mu] plane (13) (max [epsilon]) - line 3 , which is a hyperbola:

and its asymptote - line 4:

$$
\mu^{2}+\varphi^{2}=\varphi m
$$

$$
\mu=m / 2+\varphi
$$

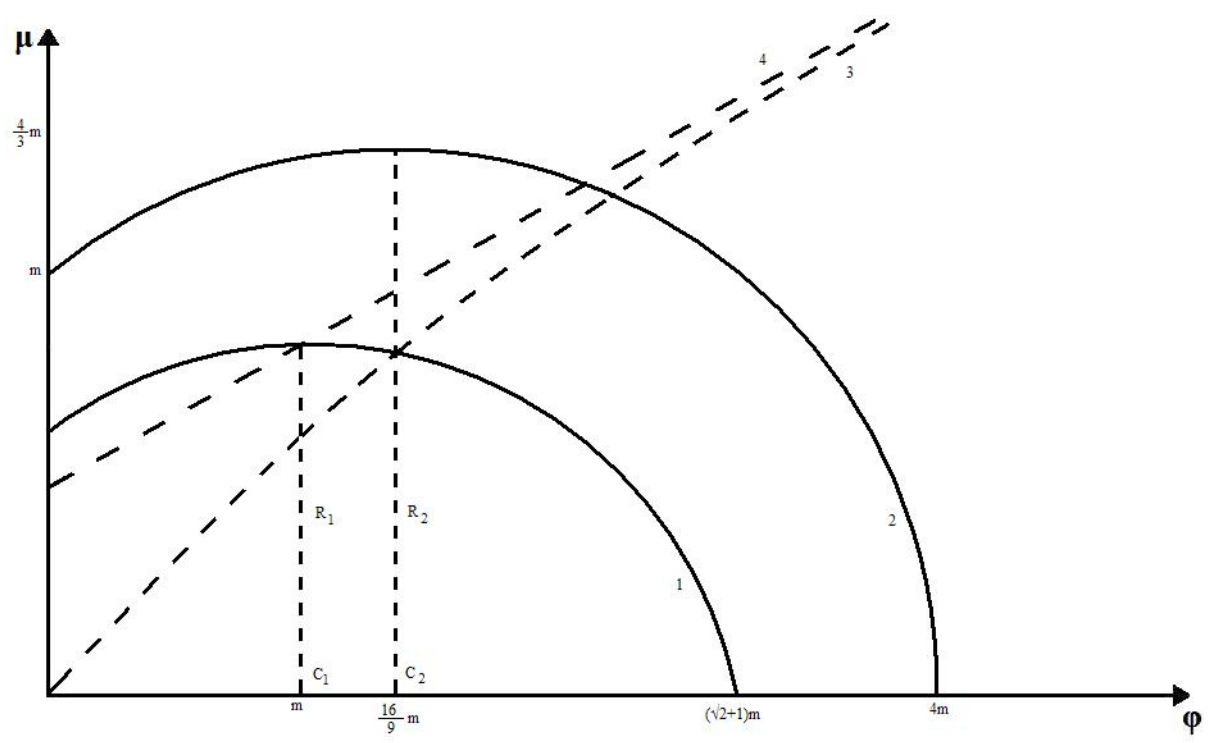

Figure 3. Surface traces[epsilon] =const (13)

Note. 1 - [epsilon] $=\sqrt{0.5} ; 2$ - [epsilon] $=0,8 ; R_{1}=\sqrt{2 m} ; R_{2}=(20 / 9) m ; 3-$ max [epsilon] line projection on the [phi] [mu] plane; 4 - asymptote for line 3 . 
The figure shows that, to preserve a constant value by the quantity of [epsilon], while increasing the value of [mu] from $[\mathrm{mu}]=0$ (at [phi] max) to $[\mathrm{mu}] \max =\mathrm{Ri}-$ it's necessary to decrease the value of [phi] (reduction in modulus $\mathrm{G}$ ); when [phi] $<\mathrm{Ci}$, for the [epsilon] = const condition; the value of the dynamic viscosity coefficient[mu]- should also be decreased .

The revision of cloud of [phi] $=\mathrm{G} /$ [omega] is important in practical terms:

$$
\varphi_{\max }=R_{i}+C_{i} \geq \varphi \geq C_{i}
$$

A numerical example is determining the physical characteristics of the underlayment material providing a predetermined level of decrease of the seismic effect intensity of [epsilon], for the values of [epsilon] $=\sqrt{0.5}$ and [epsilon] $=0,8$ when perfectly elastic and viscoelastic material is used.

Table 1.

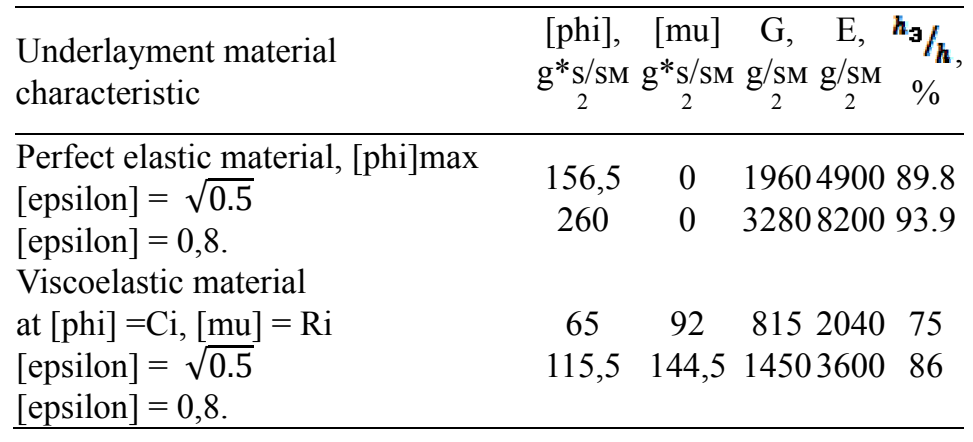

Common initial data of the problem:

- underlayment height is $\mathrm{h}=10 \mathrm{~cm}$; hə is the same one, during the operation, $\mathrm{h} \ni / \mathrm{h}=$ [sigma], E characterizes the percent reduction of the underlayment (aseismic layer) (Arnold C. A., 1994, Eisenberg, Y. M., 1998, Foo, S. and M. Cheung, 2004);

- the period and base oscillation frequency $-T=0.5 c, \omega=2 \pi / T=12.56 c^{-1}$;

- structure weight and mass - $\mathrm{Q}=2000 \mathrm{t}=2 * 109 \mathrm{G} ; \mathrm{M}=\mathrm{Q} / \mathrm{g} ; \mathrm{g}=981 \mathrm{em} / \mathrm{s} 2$;

- area of bearing on the structure bottom slab - $\mathrm{F}=400 \mathrm{~m} 2=4 * 106$;

- the average value of the vertical pressure on the ground [sigma] in $=\mathrm{Q} / \mathrm{F}=0.5 * 103 \mathrm{~g} / \mathrm{sm} 2$;

$$
m=\frac{M \omega h}{F}=\frac{\sigma_{b} \omega_{h}}{g}=0.5 * 10^{3} * 12.56 * \frac{10}{981}=65^{c} / \mathrm{cm}^{2}
$$

- E and G - Young's modulus and modulus in shear, respectively; E $=2(1+$ [upsilon] $) \mathrm{G}$, where [upsilon] Poisson's ratio, assumed to be equal to 0.25 .

Table 1 shows the payroll results of the $\mathrm{E}$ and $\mathrm{G}$ moduli, and the percentage of he $/ \mathrm{h}=[$ sigma] in / $\mathrm{E}$ characterizing the percent reduction of the underlayment (Roaf, S. et al., 2010; Unger, D. J., 1995., Ulomov, V. I., 2006).

\section{Conclusion}

The analysis of the available constructive systems, articles, publications and patents on this subject shows that a lack of close structurally analog systems of seismoisolation is the failure to provide of the general rigidity and solidity of the building, impossibility of movement of the building in all directions at a size of shift of the basis at an earthquake, and also forecasting of a balnost of a construction. The conclusion is, that using the numerical value of [epsilon] obtained by the above method gives an opportunity to determine the value of seismic magnitude for the structure in consideration taking into account the regulation seismic magnitude value for the region.

\section{References}

Abowski, N. P., Palagushkin, M. V., \& Lapeev, V. I. (2010). A systematic approach to seismic isolation of buildings in difficult ground conditions. Housing construction.

Arnold, C. A. (1994). Buildings at Risk: Seismic Design Basics for Practicing Architects. Washington, DC: AIA/ ACSA Council on Architectural Research. Malhotra, PK, 1998. Dynamics of seismic impacts in 
base-isolated buildings. Earthquake Engineering \& Structural Dynamics, 12, 797-813.

David J. Unger. (1995). Small-Scale Yielding versus Exact Linear Elastic Solutions. Analytical Fracture Mechanics, 261-284. http://dx.doi.org/10.1016/B978-012709120-4/50006-1

Eisenberg, Y. M. (1998). Seismic isolation of buildings in Russia and the CIS. Earthquake Engineering, 1, 23-26. Seismic isolation structures. - Moscow: Publishing house "Nauka".

Foo, S., \& Cheung, M. (2004). Seismic risk reduction of operational and functional components of buildings: Standard development. 13th World Conference on Earthquake Engineering (issue 3432), pp. 18-28.

Fuller, C. R., Elliott, S. J., \& Nelson, P. A. (1996). Active Control of Vibration (pp. 185-221). Virginia Polytechnic Institute and State University, Blacksburg, VA, USA. http://dx.doi.org/10.1016/B978-012269440-0/50007-8

Geniyev, G. A., \& Mamaeva, G. V. (2000). Influence of structural system of building on the seismic motion of the viscoelastic soil surface. Earthquake Engineering. Security structures, 2, 26-28.

Harrison, H. R., \& Nettleton, T. (1997). Rigid Body Motion in Three Dimensions. Advanced Engineering Dynamics (pp. 55-84). http://dx.doi.org/10.1016/B978-034064571-0/50004-7

Harrison, J. (2006). Sustainable materials for the built environment. Advanced Civil Infrastructure Materials: Science, Mechanics and Applications (pp. 271-347). http://dx.doi.org/10.1533/9781845691172.271

Krupko, T. Y. (June 2010). Safety in construction. Siberian house, 6(78), 38-43.

Kuznetsov, S. V. (2014). Lamb waves in anisotropic plates. Acoustical Physics, 60, 95-103. http://dx.doi.org/10.1134/S1063771014010084

Liu, T., Zordan, T., Briseghella, B., \& Zhang, Q. (2014). An improved equivalent linear model of seismic isolation system with bilinear behavior. Engineering Structures, 61, 113-126. http://dx.doi.org/10.1016/j.engstruct.2014.01.013

Mamaeva, G. V., Geniyev, G. A., \& Kurbatov, V. L. (2001). Seismic isolation properties of the base course. Earthquake Engineering. Structures security, 2, 40-42.

Mokhtari, M. A., Ulomov, V. I., Polyakova, T. P., \& Medvedeva, N. S. (2003). Geodynamic origin of variations of seismic regime of Caspian area and level of Caspian Sea. 4-th International Conference on Seismology and Earthquake Engineering (issue 119), pp. 33-36.

Recommendations for the design of buildings with seismic isolation sliding sash and dynamic damper (1984). CNIISK.

Roaf, S., Crichton, D., \& Nicol, F. (2010). Adapting buildings and cities for climate change (2nd ed.). 21st century Survival Guide, 373-385. http://dx.doi.org/10.1016/B978-1-85617-720-7.00024-3

Smirnov, V. I. (1997). Seismic isolation of buildings and structures. Industrial and Civil Engineering, 12, 37-39.

Ulomov, V. I. (2006). Chronicle of the seismicity of the Earth. Echoes of distant earthquakes. The Earth and the Universe, 3, 102-106.

Unger, D. J. (1995). Small-Scale Yielding versus Exact Linear Elastic Solutions.

Kurbatov, V. L., Nazin, V. V., \& Sinaev, B. A. (1999, July 10). Patent \# 2132919, E 04 C 6 H 9/02, "Earthquake building."

\section{Copyrights}

Copyright for this article is retained by the author(s), with first publication rights granted to the journal.

This is an open-access article distributed under the terms and conditions of the Creative Commons Attribution license (http://creativecommons.org/licenses/by/3.0/). 